\title{
Saúde mental da mulher: a utilização do grupo como ferramenta terapêutica para promover bem-estar, autoestima e qualidade de vida
}

\author{
Women's mental health: the use of the group as a therapeutic tool to promote welfare, self- \\ esteem and quality of life
}

Salud mental de la mujer: el uso del grupo como herramienta terapéutica para promover el bienestar, la autoestima y la calidad de vida

Elias Neves do Nascimento Filho ${ }^{1 *}$, Alex Viana de Brito², Douglas Ferreira Rocha Barbosa ${ }^{3}$, Ediane Gonçalves $^{3}$, Rosa Layse Saboya de Melo ${ }^{3}$, Isamara Santos da Silva ${ }^{3}$, Romilson da Silva Nunes ${ }^{4}$, Caio César da Silva Barros ${ }^{5}$, Lilian Maria Vasconcelos ${ }^{6}$, Darliane Keila de Lima Xavier Valença ${ }^{1}$.

\section{RESUMO}

Objetivo: Promover saúde através da criação de um grupo terapêutico direcionado as mulheres com o foco nos transtornos mentais comuns em uma cidade do Ceará. Métodos: Trata-se de uma pesquisa-intervenção, que teve como cenário o Centro de Saúde da Família (CSF) referido. Os sujeitos da pesquisa foram mulheres que apresentam algum sofrimento psíquico. A intervenção aconteceu em três etapas sendo a primeira um momento em roda para com as Agentes Comunitários de Saúde (ACS), a segunda para a leitura de prontuários para selecionar potenciais participantes para o grupo e a terceira etapa foi à criação do grupo, realizado em seis encontros semanais. Resultados: No início do mês de outubro de 2016 foi realizado o primeiro momento com as ACS, foi feito o convite às usuárias para o primeiro encontro, onde o tema dos próximos cinco encontros foram escolhidos pelas participantes, os temas abordados foram: depressão/ansiedade, cineterapia, oficina de confecções, estresse e o último sobre autoestima. Conclusão: O grupo terapêutico mostrou-se eficiente para o alcance dos objetivos deste estudo, pois em cada encontro emergiu a confiança entre as participantes e elas passaram a se apoiar, a partir do momento em que iam se identificando umas com as outras.

Palavras-chave: Grupo terapêutico e cuidado, Saúde mental, Saúde da mulher, Estratégia saúde da família.

\section{ABSTRACT}

Objective: Promote health through the creation of a therapeutic group aimed at women with a focus on common mental disorders in a city in Ceará. Methods: This is an intervention research, which took place at the Family Health Center (CSF) referred to. The research subjects were women who have some psychological distress. The intervention took place in three stages, the first being a round-the-clock moment with Community Health Agents (CHA), the second for reading medical records to select potential participants for the group and the third stage was the creation of the group, carried out in six weekly meetings. Results: At the beginning of October 2016, the first moment with the CHWs was held, the users were invited to the first meeting, where the theme of the next five meetings was chosen by the participants, the topics covered were: depression/anxiety, cinetherapy, clothing workshop, stress and the last one about self-esteem. Conclusion: The therapeutic group proved to be efficient in achieving the objectives of this study, since in each meeting the trust between the participants emerged and they started to support each other, from the moment they started to identify with each other.

Keywords: Therapeutic and care group, Mental health, Women's health, Family health strategy.

${ }^{1}$ Associação Pestalozzi de Maceió, Maceió - AL. *E-mail: elias_max_@hotmail.com

2 Centro Universitário INTA, Sobral - CE.

${ }^{3}$ Faculdade Estácio de Alagoas, Maceió - AL.

${ }^{4}$ Centro Universitário Tiradentes (UNIT), Maceió - AL.

${ }^{5}$ Academia de socorristas do APH (ASAPH), Maceió - AL.

${ }^{6}$ Centro de Reabilitação, São Luiz do Quitunde - AL. 


\section{RESUMEN}

Objetivo: Promover la salud mediante la creación de un grupo terapéutico dirigido a mujeres con enfoque en trastornos mentales comunes en una ciudad de Ceará. Métodos: Se trata de una investigación de intervención, que se llevó a cabo en el Centro de Salud de la Familia (CSF) mencionado. Los sujetos de la investigación fueron mujeres que tenían algún malestar psicológico. La intervención se llevó a cabo en tres etapas, la primera fue un momento de 24 horas con Agentes de Salud Comunitarios (CHA), la segunda de lectura de historias clínicas para seleccionar a los posibles participantes del grupo y la tercera etapa fue la creación del grupo, realizada en seis reuniones semanales. Resultados: A principios de octubre de 2016 se realizó el primer momento con los TSC, los usuarios fueron invitados a la primera reunión, donde los participantes eligieron el tema de las próximas cinco reuniones, los temas tratados fueron: depresión/ansiedad, cineterapia, taller de indumentaria, estrés y el último sobre autoestima. Conclusión: El grupo terapéutico demostró ser eficaz en la consecución de los objetivos de este estudio, ya que en cada encuentro surgió la confianza entre los participantes y empezaron a apoyarse, desde el momento en que empezaron a identificarse entre sí.

Palabras clave: Grupo terapéutico y asistencial, Salud mental, Salud de la mujer, Estrategia salud de la familia.

\section{INTRODUÇÃO}

A saúde no Brasil vem introduzindo ao longo dos anos diversos conceitos de promoção e prevenção à saúde desde o movimento da reforma sanitária, desencadeada no final da década de 70 e culminando com a $8^{\text {a }}$ Conferência Nacional de Saúde, onde se criou o Sistema Único de Saúde (SUS), sendo publicado oficialmente na Constituição de 1988. A Estratégia Saúde da Família (ESF) se propõe a considerar o usuário inserido em seu território e suas condições de vida que determinam o processo de adoecer, produzir saúde e viver das pessoas (PERES EMA, 2002).

O SUS tem como lei orgânica a 8080/90, que em seu art. $3^{\circ}$, compreende a saúde como consequência de seus fatores determinantes e condicionantes, entre outros a alimentação, moradia, saneamento básica dentre outros (BRASIL, 1990). Diversos elementos constituem-se como base para a operacionalização do SUS, como um conjunto de unidades de saúde, serviços e ações que interagem com a visão de estabelecer atividades de promoção, proteção e recuperação da saúde. (BRASIL, 2000).

Perante o tão complexo propósito e com a finalidade de reorientar o modelo assistencial de saúde, nasce o Programa Saúde da Família (PSF), para possibilitar e concretizar os princípios do SUS que consiste em uma estratégia de reorganização da atenção primária em saúde ou atenção básica, sendo denominada atualmente de ESF (BRASIL, 2007).

A ESF atua em um território geograficamente demarcado, contando com uma ou mais equipes mínimas que é composta por médicos, enfermeiros, dentistas, auxiliares de dentistas, técnicos de enfermagem, agentes administrativos e agentes comunitários de saúde (ACS) (PRATA NISS, et al., 2017).

A Reforma Psiquiátrica gerou uma movimentação histórica e revolucionária no Brasil, passando a quebrar diversos paradigmas da assistência psiquiátrica, que sempre foi centrada no regime hospitalocêntrico. A partir dessa reforma, nas décadas de 1970 e 1980 surge como proposta inovadora a desinstitucionalização do usuário (FORTE FLDS, et al., 2015).

Atualmente ainda nota-se uma falta de ações voltadas para a saúde mental no âmbito da atenção primária, apesar dos profissionais referirem e reconhecerem a necessidade em $97 \%$ dos pacientes atendidos na unidade de saúde e do elevado índice na população adulta de casos com sintomas ansiosos, depressivos ou de origem psicossomática (SOUZA AJF, et al., 2007).

É notória a grande sobrecarga de limitações que os transtornos mentais causam na qualidade de vida das pessoas. No Brasil e no mundo, com o processo de transição epidemiológica, a carga de doenças relacionadas aos agravos não transmissíveis tem-se elevado rapidamente e sua prevenção tem sido o maior desafio para saúde pública (SANTOS EG e SIQUEIRA MM, 2010). 
Tais situações caracterizam um ponto de dificuldade para a baixa inclusão da saúde mental na atenção básica, a falta de capacitação dos profissionais. Destaca-se o acúmulo de responsabilidade dos mesmos, apesar de não justificar a ausência de ações em saúde mental, pois o princípio da universalidade deve ser preservado (GONÇALVES DM e KAPCZINSKI F, 2008).

Para Cardoso C e Seminotti N (2006), o grupo é entendido pelos usuários como um lugar onde ocorre o debate sobre a necessidade de ajuda de todos. Alguns pacientes acham importante ouvir as experiências de vida dos colegas e aprender com os relatos (PELUSO ETP, et al., 2001). O objetivo deste estudo foi o de promover saúde através da criação de um grupo terapêutico direcionado as mulheres com o foco nos transtornos mentais comuns no território do Junco no município de Sobral - CE.

\section{MÉTODOS}

Trata-se de uma Pesquisa de Intervenção com abordagem qualitativa. Teve como profissional de referência um Terapeuta Ocupacional ligado ao Programa de Residência Multiprofissional em Saúde da Família (RMSF) e profissionais de apoio.

Foi escolhido como cenário de desenvolvimento da intervenção por estar localizado no território de atuação do pesquisador e apresentar fragilidade em relação à organização da demanda em saúde mental. Segundo Gil AC (2014), o projeto de intervenção tem como propósito identificar um problema de saúde coletiva a partir das observações da prática profissional.

Envolveu um grupo de 20 pessoas do sexo feminino com transtornos mentais comuns (Depressão e Ansiedade), na faixa etária de 18 a 60 anos de idade. As mesmas foram identificadas a partir das leituras nos prontuários realizadas no Centro de Saúde da Família (CSF) Junco pelas equipes: mínima e de apoio, bem como nos atendimentos e interconsultas.

Os critérios de participação das usuárias nos grupos atenderam a algumas observações pessoais e das indicações das ACS, selecionando as mulheres que faziam uso de medicações e/ou que já passaram por algum sofrimento psíquico, e que queriam buscar meios para não precisar voltar ao uso de psicotrópicos, os critérios de exclusão foram mulheres com transtornos mais graves.

Foram utilizados nomes de tipos de flores para preservar a identidade das participantes. A realização das oficinas ocorreu após ser pactuado com a gerência do serviço, em razão de outras atividades desenvolvidas habitualmente no CSF. Foi utilizado o Círculo de Cultura como referencial teórico-metodológico, esse método é constituído de três etapas.

Como instrumentos de coleta de dados para a primeira etapa do método (levantamento do universo vocabular) foram utilizados: diário de campo sendo importante por conter anotações diárias do pesquisador acerca do que é observado num determinado espaço de investigação, a pesquisa documental nos prontuários dos participantes do grupo, armazenados no Serviço de Arquivo Médico e Estatística (SAME), norteando acerca dos itinerários terapêuticos das usuárias. Onde a análise documental, para Sousa J, et al. (2011), permite a identificação, organização e localização de informações acerca de fatos de determinados momentos.

$\mathrm{Na}$ etapa 2, foi realizado o primeiro encontro do grupo com o objetivo de promover a conscientização acerca dos problemas cotidianos enfrentados pelas mesmas, de suas dificuldades, de suas alegrias, o que compreendem do mundo e o conhecimento que tem da realidade social, estimulando a capacidade critica.

Para a etapa 3 foram organizados temas pelas participantes do primeiro encontro. Nesta etapa aconteceram as demais oficinas, que foram didáticas e previamente planejadas pelos facilitadores do grupo. A realização das oficinas foi semanal, às quartas-feiras no horário de 16 h00min as 17 h00min no CSF.

Foi utilizada a análise do discurso para analisar os dados coletados durante as oficinas realizadas no CSF, que para Minayo MCS (2013), a análise de discurso visa-se conhecer as construções ideológicas do texto, ou seja, quais ideologias estão por trás das falas dos interlocutores. Essa pesquisa teve seu parecer aprovado sob número de protocolo do Comitê de Ética e Pesquisa: 0155/2016. 
No último encontro do grupo foi organizada uma roda de conversa com as participantes para avaliação da dimensão da proposta aplicada nas oficinas, bem como para saber a importância do grupo terapêutico na qualidade de vida delas.

Em todas as etapas da realização desse estudo que se enquadrou na modalidade de pesquisa de risco mínimo, foram seguidas as normas e diretrizes da Resolução $N^{\circ} 466$ de 12 de dezembro de 2012, do Conselho Nacional de Saúde, que regulamenta a pesquisa envolvendo seres humanos, e que incorporam em seu contexto os quatros referenciais básicos da bioética que inclui: beneficência, não-maleficência, autonomia e justiça, os quais passamos a descrever (BEAUCHAMP TL e CHILDRESS JF, 2002).

\section{RESULTADO E DISCUSSÃO}

As intervenções do grupo terapêutico aconteceram no CSF do Junco. O grupo tinha por objetivo identificar, por meio das atividades e temáticas abordadas, as dificuldades e desafios de cada usuária, buscando sempre a resolução dessas dificuldades e fazendo com que elas conseguissem encontrar formas de lidar mais efetivamente com conflitos pessoais vividos em outros meios e grupos sociais como: a família, os amigos, no ambiente de trabalho, no ambiente doméstico, dentre outros espaços.

Também tinham por objetivo prepará-las e estimulá-las para a realidade e o convívio pessoal e em sociedade tornando-as mais otimistas em relação à vida. Os primeiros momentos da intervenção foram com os ACS com o objetivo de explicá-los sobre o projeto e a contribuição dos mesmos para mapear as usuárias da sua área que se enquadrassem na proposta do grupo.

Após foi exibido um vídeo de sensibilização onde os mesmos foram tocados acerca da problemática e assim ao final em uma roda de conversa, expressaram opiniões positivas da real necessidade desse grupo na unidade, pois muitos deles conheciam várias usuárias dentro desse perfil. Ao final foi pactuado um horário mais adequado para a realização do grupo e agendado um segundo momento individual com cada ACS para a leitura dos prontuários.

Nise da Silveira renomada médica psiquiatra brasileira alagoana conforme citado por Cavalcanti $\mathrm{A}$ e Galvão C (2007) fala que, no livre fazer, o curso das emoções, dos afetos e das lembranças e a lógica do pensamento não estão sendo exigidos podendo, ao contrário, estar sendo exercidos por cada paciente.

Dando continuidade a intervenção, no dia 22 de novembro de 2016 aconteceu o primeiro encontro do Grupo de Mulheres, ocorreu na sala de reunião do CSF do Junco. Onde se pôde contar com o apoio da Educadora Física do sistema, Assistente Social, Enfermeira, Psicólogo da Residência Multiprofissional em Saúde da Família e uma interna de enfermagem.

Logo após foi iniciada uma dinâmica de apresentação. Na parte central da roda foram espalhados vários objetos no chão como: Bíblia, terço, gibi, flor, batom, esmalte, fone de ouvido, pelúcia, dentre outros. Cada participante foi convidada a pegar algum objeto que the fosse especialmente significativo, alguma coisa que guarde em si uma história que faça do objeto algo especial.

Nesse momento elas saudavam o grupo, falavam seu nome, onde moravam, quem as convidou para o grupo, se foi uma ACS ou o próprio pesquisador, e falavam em seguida porque escolheram determinado objeto. Muitas delas escolheram a Bíblia e se expressaram:

"Escolhi a Bíblia porque a partir do pouco que passei a conhecer a Palavra de Deus, vi sentido em minha vida e enxergar que o outro dia a Deus pertence e que ELE não mim prometeu ouro e sim suprir minhas necessidades e hoje sei plenamente que tenho sede da palavra e que eu sou capaz porque ELE é comigo Sempre." (Entrevistado 1).

Percebeu-se nesse momento o quanto a religião tem uma forte ligação para algumas e o quanto as ajudam a se reerguer. Pereira J e Ribeiro I (2012) falam que para ter um atendimento integral daqueles que buscam estes serviços, não se pode jamais desconsiderar a dimensão religiosa destas usuárias. Após esse momento de apresentação, passou-se para outra atividade com o intuito de conhecer mais cada mulher ali presente. 
$\mathrm{Na}$ parede da sala estavam espalhadas várias frases: Saúde pra mim é... Tenho medo de... Uma lembrança feliz foi quando... Meu maior desejo é... Eu sonho em... O que eu mais gosto em mim é... Isso eu faço de melhor... Meu maior medo... Muitas escolheram falar de coisas positivas em sua vida como uma boa lembrança ou de um sonho. Algumas das frases estão expressas a seguir:

"Que Deus possa me abençoar e realizar. Eu sonho em terminar a reforma da minha casa e outro sonho que eu sei que só Deus, que é de ter a cura do meu filho." (Entrevistado 2).

Em seguida, no centro da roda, foram dispostas algumas palavras/figuras geradoras para dialogar e construir um cronograma de temas a serem trabalhados de acordo com o interesse delas nos próximos encontros. Foram 10 figuras/palavras como: Lazer, Autoestima, Cinema, Música, Culinária, Depressão, Ansiedade, Estresse, Medicações, Oficina de arte e de confecções e Jogos e brincadeiras.

"Eu escolhi as medicações porque eu tomo muito remédio e não quero tomar mais nenhum, por isso escolhi esse tema para saber mais dos efeitos desses remédios." (Entrevistado 3).

Nesse momento deu para dialogar ainda mais, onde muitas falaram sobre o fato de tomar medicação, de que já pensaram em parar de tomar por conta própria, enquanto a outra falou que não era assim e que podia piorar a situação, que pararia só se o médico falasse que podia e com isso já deu pra perceber o quanto o grupo já estava fluindo.

Não sobrou nenhuma figura no chão e muitas se mostraram muito empolgadas para iniciar os temas. 0 segundo encontro foi realizado no dia 30 de outubro de 2016. A atividade com o grupo de mulheres, que estavam todas organizadas em círculo, que de acordo com a metodologia freiriana, a figura geométrica do círculo favorece o diálogo e discussão, pois todos se olham e se veem.

A abordagem do profissional de saúde partiu primeiramente do conhecimento prévio das usuárias sobre o tema. Havia perguntas em papel madeira sobre: O que é depressão; O que é ansiedade; quais os sintomas da depressão; quais os sintomas da ansiedade e quais os tratamentos. Quem iria construir os conceitos eram as próprias participantes baseadas em sua própria realidade. Algumas das respostas a seguir mostram 0 conhecimento das mulheres sobre o que é a depressão:

"[...] é uma doença miserável, se a pessoa não clamar por Deus, não consegue se livrar dela. É como se você tivesse dentro de um túnel escuro onde não se ver uma luz, nem uma saída. É uma coisa triste. A pessoa perde as forças, não tem vontade de tomar banho, não tem vontade de se arrumar. Não tem vontade de sair. Não tem vontade de nada. Tudo é triste, tudo sem graça." (Entrevistado 4).

Sobre os sintomas da depressão que elas sentiam falaram: tristeza profunda, isolamento, irritabilidade, choro fácil, baixa autoestima, pensamento suicida, insônia, falta de apetite, medo, tensão, memória falha. De acordo com Sartotius N (2005), a depressão é uma síndrome psíquica caracterizada por desânimo e sentimentos como melancolia, irritação ou temor.

Dando seguimento a partir das falas das mulheres, continuou a atividade buscando intercalar as informações prévias trazidas pelas mesmas com o complemento do facilitador, de modo a transformar e ressignificar sempre na tentativa de despertar o senso de análise crítica entre elas.

Uma participante ao ser confrontada com a pergunta "para você o que é a depressão?", prontamente afirma que ela é "uma doença que causa tristeza, desânimo". E a partir desta percepção pudemos enriquecer e complementar a informação sobre a doença, instigando-as ao debate. Em seguida foi discutido sobre ansiedade e foram ouvidas as afirmações seguintes:

"Eu sofro de ansiedade, tomo remédio pra dormir, quase todo dia sentia um grande desconforto no peito queria saber se vocês também já sentiram isso?" (Entrevistado 5). 
A ansiedade e a preocupação acentuadas ou sintomas físicos causam sofrimento e prejuízos significativos no funcionamento social, ocupacional e em atividades de lazer da pessoa que sofre disso. Então foi lançada a pergunta: "Quais as formas de tratar a depressão e a ansiedade?" e a mesmas responderam: Suporte familiar, medicação correta, ocupar a mente, procurar profissionais da saúde, aceitar a situação que tá passando, aceitar o tratamento, passear, ler livros, fazer exercícios, interagir com as pessoas.

O que foi observado também por Veras AB e Nardi AR (2008) que dizem que as mulheres costumam trazer queixas de problemas de relacionamentos com parceiros íntimos e perdas de vínculos sociais e familiares, sendo afetadas pelos desdobramentos dos relacionamentos interpessoais.

Trabalhar e possibilitar assim os relatos de experiência e de vida dessas mulheres diante do grupo acaba sendo um instrumento precioso, pois através da escuta e da fala da outra, elas se veem, se identificam, tornam-se apoio e estímulo ao autocuidado, como uma que disse:

"Ah! eu também não tinha coragem de sair de casa e vi que não era a solução ficar trancada, é muito bom sair e interagir, ver que não estamos sozinha nisso como agora e nesse momento as outras mostraram-se concordar, balançando positivamente a cabeça." (Entrevistado 4).

Portanto é de fundamental importância que os profissionais da unidade trabalhem a partir dos relatos dessas mulheres e suas vivências nos grupos e também nos atendimentos, pois esse momento de escuta gera autonomia. Elas acabam descobrindo que cada uma tem suas potencialidades, bem como as ajudam sobre as diversas formas de lidar com os problemas.

Ao final foi realizada a avaliação do momento com o uso das placas com as carinhas, onde elas falaram que o momento foi muito bom, leve, que achou o momento importante porque pôde ouvir e aprender com a outra. Havia completado duas horas de grupo e elas falaram que nem tinham notado o tempo passar, lancharam, se abraçaram e escolheram o que queriam no encontro seguinte. Uma Sessão de Cinema.

Encontro final de intervenção realizado em 25 de Janeiro de 2017 tendo como objetivo principal trabalhar a autoestima, para fazer com que ela deixe de ser um ponto negativo na vida dessas mulheres, pois pessoas que tem autoestima baixa podem deixar de acreditar em si mesmas e isso acaba afetando o dia a dia delas.

Foi realizada uma atividade objetivando estimular o relacionamento interpessoal, a comunicação e a formação de conceitos sobre a autoestima e de como elas podem desenvolvê-la e aplicá-la no dia a dia. Então inicialmente foi perguntado sobre o que elas entendiam por autoestima e se teve respostas muito ricas sobre a temática como vistas a seguir:

"Autoestima pra mim é tá de bem com a vida, conseguir me olhar no espelho, acordar e dizer assim: hoje eu estou linda! Mesmo que alguém diga assim: tú tá feia, mas se eu me acho linda e gosto de mim, o resto não interessa." (Entrevistado 3).

Houve uma grande exaltação positiva delas na hora que foi lida a frase de que elas eram a pessoa mais importante. Foi feita também a pergunta de como elas podem fazer para defender sua autoestima quando fossem atacadas, apareceu a religiosidade novamente.

Palavras como respeito, o amor próprio, pelos outros e a crença em Deus e em si mesmo foram utilizadas o tempo todo durante o encontro. Onde o amor próprio compreendido como a valorização dos próprios sentimentos e vontades apareceu nas falas, bem como da autoconfiança e do reconhecimento dos próprios limites.

A questão do autoconhecimento também foi trabalhada com elas. Pois a medida em que, quanto mais a pessoa se conhece é que é possível aceitar-se e, consequentemente, amar-se e confiar em si mesma. A partir disso, percebemos o quanto esses sentimentos influenciam umas nas outras, permitindo o estabelecimento saudável de uma boa autoestima.

Foi um momento ímpar de conversa e reflexão que fluiu de uma forma tão natural, onde o diálogo imperou e a ajuda mútua, pois uma passou a confortar e a fortalecer a outra, como uma que falou que se comprometeria a orar pela outra, dentre diversas palavras de otimismo como você vai sair dessa e você vai ficar boa apareceram nas diversas vezes na fala delas. 
A dinâmica seguinte foi a do presente, que é uma das atividades mais aplicadas em grupos, equipes de trabalho, confraternizações. Sendo ideal para aplicar nesse encontro, pois ela passa uma mensagem especifica para cada participante, além de estimular a integração, a motivação e a autoestima, tendo em vista que alguém vai reconhecer uma característica boa em cada uma e oferecer o presente.

O momento se inicia fazendo-se um sorteio, onde o facilitador fala que trouxe apenas um presente e que pra ser justo irá sortear, entregando o presente e dizendo que ela só poderá abrir depois que ouvir a mensagem.

A pessoa que recebe o presente deve ouvir a mensagem e logo em seguida escolher uma pessoa que se identifique com o teor da mensagem, nesse momento o facilitador passa a mensagem para que essa pessoa leia e entregue o presente e assim por diante. A última pessoa a receber o presente é que irá abri-lo e fará a distribuição dos bombons a todos os participantes.

Palavras como: a mais feliz, mais otimista, mais inteligente, mais organizada, mais simpática, mais corajosa, dentre outras, foram uma das características lidas. Todas receberam uma ou mais de uma qualidade e ficaram muito felizes quando escolhidas, se descontraíram muito como uma participante que estava lendo sobre a pessoa mais elegante e a outra de brincadeira já se levantou mostrando que era ela onde todas riram muito, adorando o momento.

A sala nesse dia estava toda ambientada, com vários cenários, camarim com maquiagens, secador de cabelo e acessórios. Iniciava o momento Beleza Mulher, proporcionado para que as mesmas pudessem se olhar no espelho, se arrumar, escolher os cenários para fazer uma sessão de fotos.

Ao final foi explicada a finalização da intervenção com o facilitador atual e apresentado os novos facilitadores. Foi reforçado pelas próprias participantes sobre a importância do grupo e de não o deixar morrer, de estarem se fortalecendo cada vez mais.

\section{CONSIDERAÇÕES FINAIS}

Constata-se que o tratamento terapêutico, realizado por meio de grupos, é vantajoso e eficaz para as participantes envolvidas. Observou-se ainda que a terapia, realizada através de grupos, possibilita trabalhar objetivos distintos da terapia individual. Deve-se salientar que algumas condutas e devem ser verificadas e respeitadas, para que a terapêutica dentro do grupo seja adequada. Após os encontros notou-se que as participantes estavam mais interativas, comunicativas e com melhor autoestima, os vínculos entre elas foram fortalecidos e puderam enxergar a vida com outro panorama, estando mais autoconfiantes e independentes emocionalmente.

\section{REFERÊNCIAS}

1. BEAUCHAMP TL, CHILDRESS JF. Princípios de Ética Biomédica. (4 ed.) São Paulo: Edições Loyola, 2002.

2. BRASIL. Ministério da Saúde. Secretaria de Atenção À Saúde. Departamento de Atenção Básica. Política Nacional de Atenção Básica / Ministério da Saúde, Secretaria de Atenção à Saúde, Departamento de Atenção Básica. - 4. ed. Brasília: Ministério da Saúde, 2007.

3. BRASIL. Lei 8080 , de 19 de Setembro de 1990. Dispõe sobre as condições para a promoção, proteção e recuperação da saúde, a organização e o funcionamento dos serviços correspondentes e dá outras providências. Diário Oficial da União, Poder Executivo, Brasília, DF, 20 set. 1990.

4. BRASIL. Ministério da Saúde. Sistema Único de Saúde (SUS): princípios e conquistas. Brasília, DF, 2000. 44 p.

5. CARDOSO C, SEMINOTTI N. O grupo psicoterapêutico no Caps. Cienc. Saúde Colet., 2006; 11(3): 775-83.

6. CAVALCANTI A, GALVÃO C. Terapia ocupacional: fundamentação \& prática. Rio de Janeiro: Guanabara Koogan, 2007.

7. FERREIRA JT, et al. Os Centros de Atenção Psicossocial (CAPS): uma instituição de referência no atendimento à saúde mental. Rev. Saberes, Rolim de Moura, 2016; 4(1): 72-86.

8. FORTES FLS, et al. Trajetória histórica da reforma psiquiátrica em Portugal e no Brasil. Revista de Enfermagem Referência, 2014; 4: 117-125.

9. GIL AC. Métodos e técnicas de pesquisa social. 5. ed. São Paulo: Atlas, 2014.

10. GONÇALVES DM, KAPCZINSKI F. Prevalência de transtornos mentais em indivíduos de uma unidade de referência para Programa Saúde da Família em Santa Cruz do Sul, Rio Grande do Sul, Brasil. Caderno de Saúde Pública, 2008; 24(9): 2043-2053. 
11. MINAYO MCS. O Desafio do Conhecimento: pesquisa qualitativa em saúde. 13 ed. - São Paulo: Hucitec, 2013.

12. PELUSO ETP, et al. A experiência de usuários do serviço público em psicoterapia de grupo: estudo qualitativo. Rev. Saúde Publica, 2001; 35(4): 341-8.

13. PEREIRA J, RIBEIRO I. Análise da relação entre religiosidade e saúde mental em usuários do Centro de Atenção Psicossocial I (CAPS I) de Mirinzal-MA no período 2006-2010. Anais dos Simpósios da ABHR, 2012; 13.

14. PERES EM. A estratégia Saúde da Família e sua ajuda na consolidação do SUS. Esc Anna Nery Rev Enferm, 2002; 6(1): 115-24.

15. PRATA NISS, et al. Saúde mental e atenção básica: território, violência e o desafio das abordagens psicossociais. Trabalho, Educação e Saúde, 2017; 15(1): 33-53.

16. SANTOS EG, SIQUEIRA MM. Prevalência dos transtornos mentais na população adulta brasileira: uma revisão sistemática de 1997 a 2009. J Bras Psiquiatr, 2010; 59(3): 238-246.

17. SARTORIUS N. Transtornos depressivos. Artmed, São Paulo, 2005.

18. SOUZA AJF, et al. La salud mental en el Programa de Salud de la Família. Revista brasileira de enfermagem, 2007; 60(4): 391-395.

19. SOUZA J, et al., Análise Documental e Observação participante na pesquisa em Saúde Mental. Revista Baiana de Enfermagem, Salvador, 2011; 25(2): 221-228.

20. VERAS AB, NARDI AR. Depressão na mulher. Revista Brasileira de Medicina, 2008; 62(6): 154-163. 